\title{
Decreased $\mathrm{N}$-acetyl-aspartate/choline ratio and increased lactate in the frontal lobe of patients with Huntington's disease: a proton magnetic resonance spectroscopy study
}

\author{
L Harms, H Meierkord, G Timm, L Pfeiffer, A C Ludolph
}

\begin{abstract}
Background-Both the effect of the mutation and the pathogenesis of Huntington's disease are unknown and a lack of biological markers for the natural history of the disease impedes the evaluation of novel therapeutic approaches.

Methods-Proton magnetic resonance spectroscopy was carried out on a frontal region of the cortex in 17 patients with clinically overt Huntington's disease and four asymptomatic gene carriers.

Results-Eight of 17 (47\%) clinically affected patients with Huntington's disease and each of the asymptomatic carriers had lactate peaks in the frontal cortex which were not present in controls. The N-acetyl-aspartate/choline (NAA/Ch) ratio was significantly reduced in the symptomatic patients indicating the presence of neuronal loss. The reduction was related to the clinical severity of the disease and was absent in the asymptomatic carriers. Conclusion-The finding of lactate peaks supports the hypothesis that disturbed cerebral energy metabolism contributes to the pathogenesis of Huntington's disease.
\end{abstract}

(F Neurol Neurosurg Psychiatry 1997;62:27-30)

Keywords: Huntington's disease; lactate peaks; $\mathrm{N}$-acetyl-aspartate/choline ratio

After an increased number of CAG repeats was shown to be the genetic defect in Huntington's disease, ${ }^{1}$ efforts were concentrated on the functional consequences of the mutation, pathogenesis of the disease, and future neuroprotective strategies. There is evidence that impairment of production of chemical energy significantly contributes to the pathogenesis of striatal lesions in Huntington's disease,,$^{25}$ in particular, because inhibition of cerebral oxidative phosphorylation results in a pattern of vulnerability closely resembling the disease. ${ }^{6-8}$ As these lesions can be attenuated or prevented by antagonists to glutamate receptors, it has been postulated that the mechanism of "weak" excitotoxicity is a major contributing pathogenetic factor. ${ }^{9}$ Such a hypothesis is supported by PET studies, which show reduced glucose and oxygen metabolism of the basal ganglia and cortex in patients with Huntington's disease. ${ }^{10-12}$

We have studied the frontal cortex for sev- eral reasons. Firstly, there is neuropathological evidence that this region is involved in Huntington's disease ${ }^{13}$ but precise correlations with the development of the clinical features are as yet lacking. Secondly, recent PET studies have convincingly showed reduced glucose metabolism in various stages of clinical disease including mild and severe forms. ${ }^{11214}$ Finally, neuropsychological deficits have also been reported in Huntington's disease, which have been attributed to frontal lobe dysfunction. ${ }^{15} 16$ For these reasons, we carried out lactate measurements and determined the $\mathrm{N}$-acetylaspartate/choline (NAA/Ch) ratio by proton magnetic spectroscopy in a selected volume of the frontal lobe.

\section{Subjects and methods}

We examined 26 patients with a definitive molecular genetic diagnosis of Huntington's disease; in five of these patients the spectra could not be evaluated as choreoathetotic movements impeded the acquisition of spectroscopic data. These patients were excluded from the study. Each patient was given a clinical examination by a neurologist (HM) and subsequently the severity of the condition was defined from the Shoulson score ${ }^{17}$ and the motor score of the United Huntington's Disease Rating Scale (UHDRS)..$^{18}$ Duration of disease was defined as the time which had elapsed since the first motor symptoms appeared as judged by the patient, relatives, and referring physicians. Genetic testing was performed by standard techniques ${ }^{19} 20$ and showed that each of the patients and asymptomatic carriers had 39 CAG repeats or more (table).

From clinical criteria for severity of the disease, patients were divided into four groups.

Group I consisted of four asymptomatic gene carriers (one man, three women; mean age 43.5 (range 35-60)). Each asymptomatic gene carrier had a Shoulson score of 13 and a motor score of 0 .

Seventeen patients with Huntington's disease were clinically symptomatic; nine of these patients were men, eight were women; their mean age was $46 \cdot 1$ (range 25-70) years.

Group II comprised six patients (five men, one woman, mean age $46 \cdot 5$, range $39-56$ ) had a mean Shoulson score of 10.5 (range 10-11) and a motor score of 19.4 (range 15-24). They were classified as being "mildly" handicapped.

Group III patients (three men, three 
Characteristics, clinical severity, scale rating, medication, and NAA/Ch and lactate/Ch ratios of individual patients

\begin{tabular}{|c|c|c|c|c|c|c|c|c|c|c|}
\hline $\begin{array}{l}\text { Patient } \\
\text { No }\end{array}$ & $\begin{array}{l}\text { Sex } \\
(M / F)\end{array}$ & $\begin{array}{l}\text { Age } \\
(y)\end{array}$ & Repeats & $\begin{array}{l}\text { Duration } \\
(y)\end{array}$ & Severity & Shoulson & UHRDS & Medication & $N A A / C h$ & Lactate/Ch \\
\hline $\begin{array}{l}1 \\
2 \\
3 \\
4 \\
5 \\
6 \\
7 \\
8 \\
9 \\
10 \\
11 \\
12 \\
13 \\
14 \\
15 \\
16 \\
17 \\
18 \\
19 \\
20 \\
21\end{array}$ & $\begin{array}{l}F \\
F \\
F \\
M \\
M \\
F \\
M \\
M \\
M \\
M \\
M \\
F \\
F \\
F \\
M \\
M \\
F \\
F \\
F \\
M \\
F\end{array}$ & $\begin{array}{l}35 \\
43 \\
36 \\
60 \\
44 \\
39 \\
56 \\
55 \\
41 \\
44 \\
43 \\
42 \\
70 \\
34 \\
42 \\
47 \\
63 \\
25 \\
33 \\
56 \\
44\end{array}$ & $\begin{array}{l}46 \\
40 \\
48 \\
39 \\
45 \\
44 \\
43 \\
42 \\
44 \\
43 \\
44 \\
44 \\
40 \\
55 \\
49 \\
45 \\
44 \\
52 \\
50 \\
45 \\
47\end{array}$ & $\begin{array}{r}0 \\
0 \\
0 \\
0 \\
2 \\
7 \\
4 \\
5 \\
5 \\
9 \\
9 \\
18 \\
5 \\
5 \\
10 \\
9 \\
6 \\
15 \\
3 \\
4 \\
5 \\
14\end{array}$ & $\begin{array}{l}\text { Asymptomatic } \\
\text { Asymptomatic } \\
\text { Asymptomatic } \\
\text { Asymptomatic } \\
\text { Mild } \\
\text { Mild } \\
\text { Mild } \\
\text { Mild } \\
\text { Mild } \\
\text { Mild } \\
\text { Moderate } \\
\text { Moderate } \\
\text { Moderate } \\
\text { Moderate } \\
\text { Moderate } \\
\text { Moderate } \\
\text { Severe } \\
\text { Severe } \\
\text { Severe } \\
\text { Severe } \\
\text { Severe }\end{array}$ & $\begin{array}{r}12 \\
13 \\
13 \\
13 \\
10 \\
11 \\
11 \\
10 \\
11 \\
10 \\
6 \\
3 \\
3 \\
4 \\
4 \\
3 \\
0 \\
0 \\
1 \\
1 \\
1\end{array}$ & $\begin{array}{r}4 \\
0 \\
0 \\
3 \\
24 \\
19 \\
19 \\
23 \\
15 \\
17 \\
37 \\
55 \\
39 \\
49 \\
44 \\
50 \\
62 \\
70 \\
85 \\
74 \\
70\end{array}$ & $\begin{array}{l}\text { None } \\
\text { None } \\
\text { None } \\
\text { None } \\
\text { None } \\
\text { None } \\
\text { None } \\
T \\
\text { None } \\
T \\
T \\
T \\
T \\
T \\
\text { None } \\
\text { T, C, L } \\
\text { None } \\
T, C \\
T \\
T \\
T\end{array}$ & $\begin{array}{l}1.50 \\
1.51 \\
2.35 \\
1.59 \\
1.73 \\
2.00 \\
1.62 \\
2.34 \\
1.63 \\
1.63 \\
1.50 \\
1.66 \\
1.23 \\
1.67 \\
1.11 \\
1.27 \\
0.95 \\
1.18 \\
1.24 \\
1.40 \\
1.55\end{array}$ & $\begin{array}{l}0.35 \\
0.89 \\
0 \cdot 39 \\
0 \cdot 81 \\
0.00 \\
0 \cdot 25 \\
0 \cdot 13 \\
0.00 \\
1 \cdot 12 \\
0.00 \\
0.00 \\
0 \cdot 15 \\
0.00 \\
0.63 \\
0.00 \\
0.56 \\
0.00 \\
0.35 \\
0.00 \\
0.34 \\
0.00\end{array}$ \\
\hline
\end{tabular}

$\mathrm{T}=$ Tiaprid; $\mathrm{C}=$ clonazepam; $\mathrm{L}=$ levomepromazin.

women, mean age $46 \cdot 3$ (range 34-70) had a mean Shoulson score of 3.8 (range 3-6) and a mean motor score of $45 \cdot 6$ (range 37-55). They were classified as being in the "moderate" range of deficits.

Group IV (one man, four women, mean age 44.2 (range 25-63)) were classified as having "severe" deficits as they had a mean Shoulson score of 0.6 (range $0-1$ ) and a motor score of $72 \cdot 2$ (range $62-85$ ).

Group V consisted of 19 healthy controls. Eight subjects in this group were men, 11 were women; their mean age was 38.0 (range 22-68).

${ }^{1} \mathrm{H}$ magnetic resonance spectroscopy was performed on a 1.5 Tesla Gyroscan S 15 (Philips) system. Based on a transversal T2 SE weighted imaging ( $\mathrm{TE}=30 ; 90 \mathrm{~ms}, \mathrm{TR}=$ $2000 \mathrm{~ms}$ ) we selected a volume of $20 \times 20 \times$ $40 \mathrm{~mm}$ in a frontal area of the brain by a specially resolved spectroscopy (SPARS) sequence (fig 1). ${ }^{21}$ Water suppression was achieved by selective inversion pulse. Spectra were obtained using a headcoil after shimming to minimise inhomogenities of the magnetic

Figure 1 Volume evaluated in the left frontal cortex. field. We chose the following parameters: TE $=136 \mathrm{~ms}$, $\mathrm{TR}=2000 \mathrm{~ms}$, sample frequency $1 \mathrm{kHz}, 1024$ samples, 256 measurements. In the standard processing of spectra zero filling $4 \mathrm{k}$, Fourier transformation, and phase correction were used. Evaluation of the ratios choline $(\mathrm{Ch})$ /creatine (Cr), N-acetylaspartate (NAA)/Ch, and lactate/Ch by integration of the peaks allowed a quantitative description of metabolic alterations. The spectroscopic data were obtained and processed without knowledge of the clinical characteristics of the patient.

Spectroscopic findings were compared with clinical and molecular genetic data. Statistical comparisons were performed using the Kruskal-Wallis test, the Mann-Whitney $U$ test, and the Wilcoxon rank test.

\section{Results}

The $\mathrm{Ch} / \mathrm{Cr}$ ratios did not show any significant differences between groups (group I 1.06 $(0.06)$, group II $0.95(0.13)$, group III 0.97 $(0.07)$, group IV $0.94(0.11)$, group V 1.07 $(0 \cdot 28))$. We tried to relate the NAA/Ch ratiowhich is accepted to reflect the amount of the neuronal marker $\mathrm{NAA}^{22}$ - to the clinical findings in our patients. Whereas these ratios were indistinguishable in asymptomatic gene carriers, mildly affected patients, and controls (group I $1.73(0.41)$, group II $1.83(0.29)$, group V $1.80(0.37)$ ) (fig 2), they were decreased in group III $(1 \cdot 41(0 \cdot 24))$ and group IV patients $(1.26(0.23))$. The differences between controls (group V) and groups III (P $=0.022)$ and IV $(P=0.008)$ were significant There was no significant relation between the reduction in $\mathrm{NAA} / \mathrm{Ch}$ ratio and duration of the disease, age of the patients, and number of CAG repeats.

In the frontal cortex lactate peaks were present in eight of the 17 symptomatic patients and each of the four asymptomatic gene carriers but not in the controls (fig 3A-C; table). Nine of our patients did not have an increased lactate in the tissue volume examined. Although it seemed that duration and severity of the disease and low NAA were broadly pre- 
Figure 2 Distribution of NAA/Ch ratios in frontal cortex of patients with Huntington's disease and controls.

\begin{tabular}{|ll|}
\hline I & Asymptomatic \\
II & Mild \\
III & Moderate \\
IV & Severe \\
V & Control \\
\hline
\end{tabular}

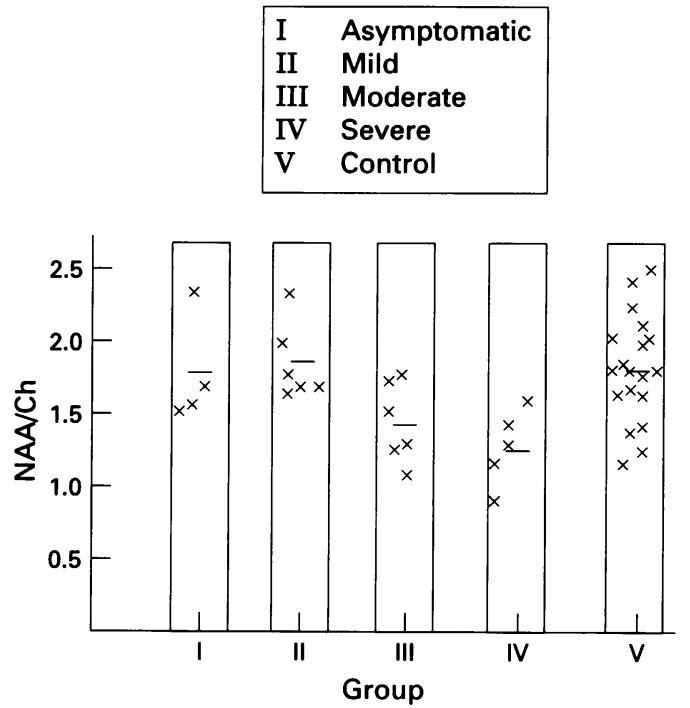

Figure 3 (A) Normal magnetic resonance spectrum in a control without a lactate peak. (B) Example of increased cerebral lactate in an asymptomatic gene carrier (patient 4, table), and (C) in a symptomatic patient with a reduced $N A A / C h$ ratio (patient 18, table).
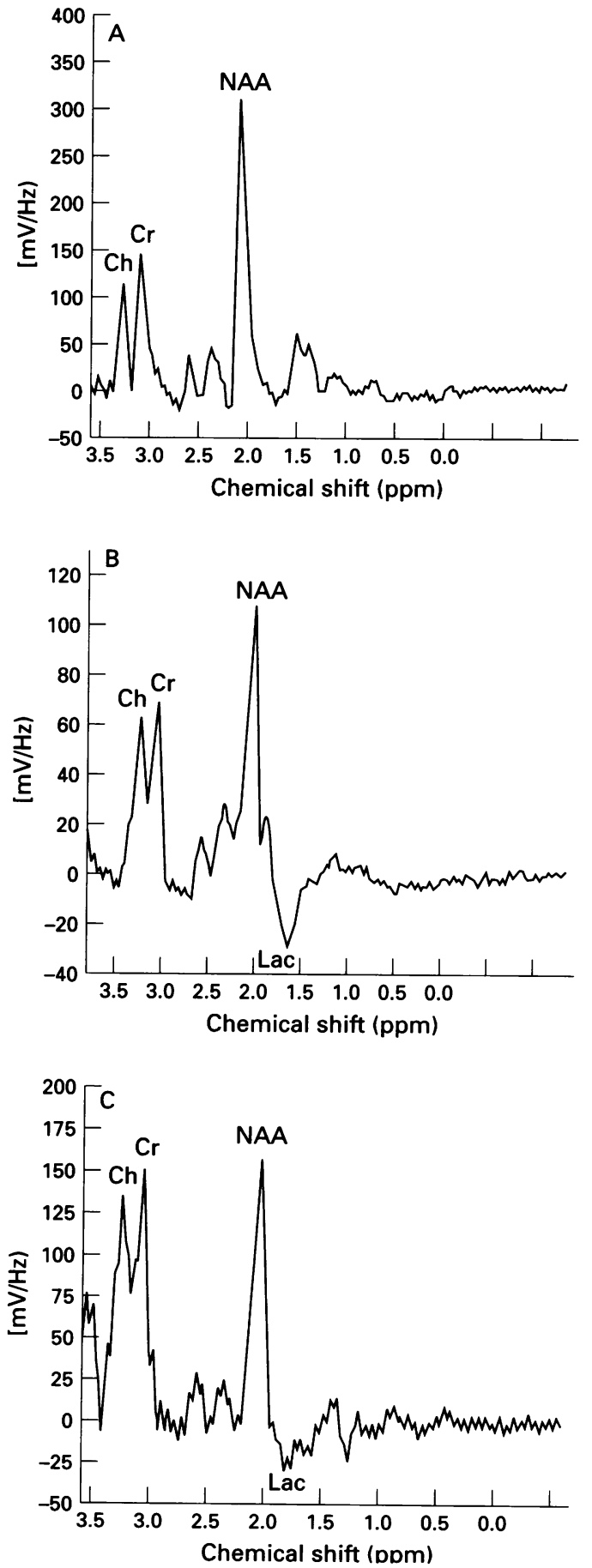

dictive of this result, exceptions obviously existed (see for example, patient 8 in the table). Results were apparently unrelated to medication as six of the patients did not receive any drug and yet lactate peaks were detected.

\section{Discussion}

We performed ${ }^{1} \mathrm{H}$ NMR spectroscopy on a well defined and identical frontal lobe region in 17 patients with clinically overt Huntington's disease and four asymptomatic gene carriers. In each of the asymptomatic carriers and in $47 \%$ of the symptomatic patients we detected cerebral lactate in the frontal cortex. This is consistent with the result reported by Jenkins $e t a l^{23}$ who found cerebral lactate in the occipital cortex of 16 patients with Huntington's disease. Our data suggest that the frontal cortex is involved early in the course of Huntington's disease. The presence of lactate concentrations supports the hypothesis that a defect of aerobic energy metabolism contributes to the pathogenesis of the disease. However, in our study cerebral lactate could be detected in only a proportion of those studied. This may be explained simply by the fact that the regions studied are of importance (frontal $v$ occipital). This conclusion is supported by other findings of Jenkins $e t a l l^{23}$ that the same patients who had raised occipital lactate concentrations showed more heterogenous results in studies of the basal ganglia. We attempted to study the basal ganglia but could not obtain high quality signals. This is presumably due to artifacts caused by paramagnetic iron which can be detected in this area of the brain and influences the spectral lines. ${ }^{24}$ Also at variance with the results of Jenkins et $a l,{ }^{23}$ is that the four asymptomatic gene carriers had greatly increased lactate peaks. In our opinion the small number of asymptomatic gene carriers studied $(\mathrm{n}=4 v \mathrm{n}=2$ in the study of Jenkins et $a^{23}$ ) does not permit further conclusions. In our study there was a tendency for lactate peaks to occur early in the disease when there was minimal or no involuntary motor disturbance and for lactate to be absent in patients with a severe movement disorder. Therefore, the pattern of our findings excludes the possibility that movement alone-such as that in the basal ganglia after finger movements ${ }^{25}$-is likely to be responsible for the lactate peaks. The variability of the results could be a property of spectroscopic measurements, which have some uncertainty; however, the standard deviations of mean values for ratios evaluated in our normal control population were comparable with those reported in the literature..$^{23} 26$ We did not detect lactate in normal controls.

Older patients with longstanding and severe disease and a decrease of NAA/Ch ratios were more likely not to have lactate in the frontal cortex. This may be simply due to neuronal loss, which does not allow lactate to increase during later stages of the disease. The result also relates to recent rodent studies which showed that the capability to respond to meta- 
bolic stress by anaerobic glycolysis is age dependent. ${ }^{27}$ This decrease in the ability to adjust to increased demands for chemical energy is found in middle aged animals and may be partly genetically determined. ${ }^{27}$ Therefore, the possibility exists that older people with Huntington's disease or patients who have had Huntington's disease for a longer time have less ability to respond to metabolic stress. Whether this idea is of relevance for the pathogenesis of Huntington's disease remains to be established.

A decreased NAA/Ch ratio indicates the presence of neuronal loss; therefore, our finding that NAA concentrations are reduced in later stages of Huntington's disease but normal in patients with less severe clinical deficits is consistent with the established knowledge that the frontal cortex is part of the degenerative process. Whether NAA can serve as a biological marker for the late disease must be shown in longitudinal studies. Davie et $a l^{28}$ and TaylorRobinson et $a^{29}$ detected increased glutamine/glutamate peaks during their magnetic resonance spectroscopic studies of symptomatic patients with Huntington's disease ( $\mathrm{n}=$ 5 and $n=3$ respectively); we did not find comparable peaks in this study.

In conclusion, this study shows that the neuronal marker NAA is preferentially reduced in late stages of Huntington's disease. Lactate can be detected in the frontal cortex of symptomatic and asymptomatic patients with Huntington's disease but a clear cut relation to the clinical course of the disease could not been shown by studies of this cortical region. Further studies should consider the natural course of alterations of aerobic metabolism in the frontal lobe of asymptomatic gene carriers. Although the presence of lactate concentrations supports the concept of a nuclear encoded energy deficit being part of the pathogenesis of Huntington's disease, our findings are less consistent than previously reported. This might be a secondary effect of reduced neuronal activity in the frontal cortex-or possibly a pathogenetic factor for the development of the disease specific lesions.

This work was supported by grants from the BMFT (9814167) to HM and ACL and DFG (982 0663) to HM.

1 Huntington's Disease Collaborative Research Group. A novel gene containing a trinucleotide repeat that is expanded and unstable on Huntington's disease chromosomes. Cell 1993;72:971-83.

2 Tellez-Nagel I, Johnson AB, Terry RD. Studies on brain biopsies of patients with Huntington's chorea. Neuropathol Exp Neurol 1974;33:178-84.

3 Goebel HH, Heipertz R, Scholz W, I qbal K, Tellez-Nagel I. Juvenile Huntington chorea: clinical, ultrastructural, and biochemical studies. Neurology 1978;28:23-31.
4 Ludolph AC, He F, Spencer PS, Hammerstad J, Sabri M. 3nitropropionic acid-exogenous animal neurotoxin and possible human striatal toxin. Can 7 Neurol Sci 1991;18. 492-6.

5 Beal MF. Neurochemistry and toxin models in Huntington's disease. Curr Opin Neurol 1994;7:542-7.

6 Brouillet EB, Jenkins BG, Hyman BT, et al. Age-dependent vulnerability of the striatum to the mitochondrial toxin 3vulnerability of the striatum to the mitochondrial
nitropropionic acid. $₹$ Neurochem 1993;60:356-9.

7 Brouillet E, Hantraye P, Dolan R, et al. Chronic administration of 3-nitropropionic acid induced selective striatal degeneration and abnormal choreiform movements in monkeys. Soc Neurosci Abstracts 1993;19:409.

8 Beal MF, Brouillet E, Jenkins BG, et al. Neurochemical and histological characterization of striatal excitotoxic lesions produced by the mitochondrial toxin 3-nitropropionic acid. $\mathcal{F}$ Neurosci 1993;13:4181-92.

9 Beal MF. Does impairment of energy metabolism result in excitotoxic neuronal death in neurodegenerative illnesses ? Ann Neurol 1992;31:119-30.

10 Kuhl DE, Metter EJ, Riege WH, Markham CH. Patterns of cerebral glucose utilisation in Parkinson's disease and Huntington's disease. Ann Neurol 1984;15 (suppl): 119-25.

11 Kuwert T, Lange HW, Langen KJ, Herzog H, Aulich A, Feinendegen LE. Cortical and subcortical glucose consumption measured by PET in patients with Huntington's disease. Brain 1990;113:1405-23.

12 Martin WRW, Clark C, Ammann W, Stoessl AJ, Shtybel W, Hayden MR. Cortical glucose metabolism in Huntington's disease. Neurology 1992;42:223-9.

13 Lange H, Thörner G, Hopf A, et al. Morphometric studies of the neuropathological changes in choreatic diseases. $\mathscr{I}$ Neurol Sci 1976;28:401-25.

14 Sedvall G, Karlsson P, Lundin A, et al. Dopamine D1 receptor number- a sensitive PET marker for early brain degeneration in Huntington's disease. Eur Arch Psychiatry Clin Neurosci 1994;243:249-55.

15 Sprengelmayer $R$, Lange $H$, Hömberg $V$. The pattern of attentional deficits in Huntington's disease. Brain 1995; 118:145-52.

16 Jason GW, Pajurkova EM, Suchowersky O, et al. Presymptomatic neuropsychological impairment in symptomatic neuropsychological impairment

17 Shoulson I. Huntington disease: functional capacities in patients treated with neuroleptic and antidepressant drugs. Neurology 1981;31:1333-5.

18 Huntington Study Group. Unified Huntington's disease rating scale: reliability and consistency. Mov Disord 1996; 11:136-42.

19 Maniatis T. Molecular cloning - a laboratory manual. New York: Cold Spring Harbor, 1989.

20 Riess O, Noerremoelle A, Soerensen SA, Epplen JT. Improved PCR conditions for the stretch of (CAG)n repeats causing Huntington's disease. Hum Mol Genet 1993;2:637.

21 Luyten PR, den Hollander JA. 'H MR spatially resolved spectroscopy of human tissues in situ. Magn Reson spectroscopy of hum
Imaging $1986 ; 4: 237-9$.

22 Birken D, Oldendorf WH. N-Acetyl-aspartic acid: a literature review of a compound prominent in ${ }^{1} \mathrm{H}-\mathrm{NMR}$ spectroscopic studies of brain. Neurosci Biobehav Rev 1989 13:23-31

23 Jenkins BG, Koroshetz WJ, Beal MF, Rosen BR. Evidence for impairment of energy metabolism in vivo in Huntington's disease using localized 'H NMR spectroscopy. Neurology 1993;43:2689-95.

24 Chen JC, Hardy PA, Clausberg M, et al. T2 values in the human brain: comparison with quantitative assays of iron and ferritin. Radiology 1989;173:521-6.

25 Kuwabara T, Watanabe H, Tsuji S, Yuasa T. Lactate rise in the basal ganglia accompanying finger movements: a localized ${ }^{1} \mathrm{H}$-MRS study. Brain Res 1995;670:326-8.

26 Gideon P, Henrikson O, Sperling B, et al. Early time course of $\mathrm{N}$-acetylaspartate, creatine and phosphocreatine, and compounds containing choline in the brain after acute compounds containing choline in the brain after acute stroke. A proton magnetic

27 Roberts EL Jr, Chih C-P. Age-related alterations in energy metabolism contribute to the increased vulnerability of the aging brain to anoxic damage. Brain Res 1995;678 $83-90$

28 Taylor-Robinson SD, Weeks RA, Sargentoni J, et al. Evidence for glutamate excitotoxicity in Huntington's disease with proton magnetic resonance spectroscopy. Lancet 1994;343:1170.

29 Davie CA, Barker GJ, Quinn N, Tofts PS, Miller DH Proton MRS in Huntington's disease. Lancet 1994;343 1580. 